Article

\title{
The Impact of Iron Adsorption on the Electronic and Photocatalytic Properties of the Zinc Oxide (0001) Surface: A First-Principles Study
}

\author{
Jingsi Cheng ${ }^{1}$, Ping Wang ${ }^{1, *(\mathbb{D})}$, Chao Hua ${ }^{2}$, Yintang Yang ${ }^{3}$ and Zhiyong Zhang ${ }^{4}$ \\ 1 State Key Laboratory of Integrated Service Networks, School of Telecommunications Engineering, \\ Xidian University, Xi'an 710071, China; jingsicheng@stu.xidian.edu.cn \\ 2 Institute of Process Engineering, Chinese Academy of Sciences, Beijing 100190, China; \\ huachao@home.ipe.ac.cn \\ 3 School of Microelectronics, Xidian University, Xi'an 710071, China; ytyang@xidian.edu.cn \\ 4 College of Electronic and Informational Engineering, Northwestern University, Xi'an 710127, China; \\ zhangzy@nwu.edu.cn \\ * Correspondence: pingwang@xidian.edu.cn; Tel.: +86-136-5923-8942
}

Received: 28 January 2018; Accepted: 9 March 2018; Published: 12 March 2018

\begin{abstract}
The structural stability, electronic structure, and optical properties of an iron-adsorbed $\mathrm{ZnO}$ (0001) surface with three high-symmetry adsorption sites are investigated with first-principle calculations on the basis of density functional theory and the Hubbard-U method. It is found that the iron adatom in the $\mathrm{H}_{3}$ adsorption site of $\mathrm{ZnO}$ (0001) surface has the lowest adsorption energy of $-5.665 \mathrm{eV}$ compared with $\mathrm{T}_{4}$ and Top sites. For the Top site, compared with the pristine $\mathrm{ZnO}$ (0001) surface, the absorption peak located at $1.17 \mathrm{eV}$ has a red shift, and the elevation of the absorption coefficient is more pronounced in the visible-light region, because the Fe-related levels are introduced in the forbidden band and near the Fermi level. The electrostatic potential computation reveals that the work function of the $\mathrm{ZnO}$ (0001) surface is significantly decreased from 2.340 to $1.768 \mathrm{eV}$ when iron is adsorbed on the Top site. Furthermore, the degradation mechanism based on the band structure is analyzed. It can be concluded that the adsorption of iron will promote the separation of photoinduced carriers, thus improving the photocatalytic activity of $\mathrm{ZnO}(0001)$ surface. Our study benefits research on the photocatalytic activity of $\mathrm{ZnO}$ and the utilization rate of solar energy.
\end{abstract}

Keywords: $\mathrm{ZnO}$ (0001) surface; first-principles; iron; optical properties; photocatalytic

\section{Introduction}

In recent years, with increasingly serious environmental pollution and energy shortage, semiconductor-based photocatalysts have aroused great interest. Normally, semiconductor photocatalytic technology is based on energy band theory. When the incident photon energy is larger than the band gap energy $\left(E_{\mathrm{g}}\right)$ of the semiconductor, electrons $\left(\mathrm{e}^{-}\right)$will be excited and promoted from the valence band (VB) to the conduction band (CB), leaving an equal number of holes $\left(\mathrm{h}^{+}\right)$behind [1]. Then, the electrons and holes will combine with $\mathrm{O}_{2}$ and $\mathrm{H}_{2} \mathrm{O}$, forming $\cdot \mathrm{O}_{2}^{-}$and $\cdot \mathrm{OH}$ to react with the organic pollutants as they spread to the surface of the semiconductor. $\mathrm{TiO}_{2}$ [2-4], $\mathrm{CdS}[5,6], \mathrm{ZnO}[7,8]$, and $\mathrm{MoO}_{3}[9,10]$ are good photocatalysts and, under a certain intensity of light irradiation, are used in wastewater treatment to degrade organic pollutants. Zinc oxide ( $\mathrm{ZnO})$, a potential semiconductor photocatalyst, has a low cost, is chemically stable, is non-toxic, and has a high photocatalytic effect on organic pollutants because of its large excitation binding energy $\left(E_{b}=60 \mathrm{meV}\right)[11,12]$. However, its photocatalytic activity is restricted to the ultraviolet (UV) region (wavelength below $400 \mathrm{~nm}$ ) of the solar spectrum by its wide band gap $(3.37 \mathrm{eV})$ at room temperature [13]. The increase of absorption coefficient in the visible light 
region can improve the utilization rate of sunlight and the photocatalytic spectrum range of $\mathrm{ZnO}$. Some experimental and theoretical works have been undertaken to enhance the absorption coefficient of $\mathrm{ZnO}$ under visible light irradiation with foreign element-doping and the surface modification of, for example, semiconductor composite and noble metal composite structures [14-18]. Yu et al. [15] revealed that the light absorption coefficient of $\mathrm{ZnO}$ in the visible light region was greatly enhanced by $\mathrm{N}$ - and C-doping through first-principle calculations. Li et al. [16] observed that doped $\mathrm{Co}^{2+}$ ions can prevent the recombination of photoinduced electron-hole pairs and decrease the optical band gap, whereas the $\mathrm{ZnO} / \mathrm{CuS}$ composite heterostructure can increase the visible light absorption coefficient and enhance the separation of photoexcited charge carriers by conducting methyl orange (MO) photodegradation experiments. Cheng et al. [18] showed that the absorption edge of $\mathrm{Ag} / \mathrm{ZnO}$ core-shell nanoparticles had a red shift and a larger light absorption coefficient compared with that of the bulk ZnO by the first-principle computations using the Vienna ab initio simulation package (VASP).

The morphology of the $\mathrm{ZnO}$ surface will induce a better photocatalytic activity because a higher surface area possesses several active sites for the interaction with pollutants [19,20]. As is known, the morphology of $\mathrm{ZnO}$ is dominated by four main low-Miller-index surfaces: polar (0001) and $(000 \overline{1})$ surfaces as well as non-polar (1010) and (1120) surfaces. Zhang et al. [21] investigated these four surfaces by first-principle calculations with VASP and confirmed that (0001)-Zn surface had the strongest absorption in the near UV region range among these four surfaces and a remarkable red-shift phenomenon of the absorption edge compared with the bulk $\mathrm{ZnO}$, indicating that (0001)-Zn surface had the highest photocatalytic activity with low photon energy. In recent years, the adsorption of the $\mathrm{Cu}, \mathrm{Co}, \mathrm{Ag}, \mathrm{Au}, \mathrm{Mg}, \mathrm{B}$, and Si atoms on the $\mathrm{ZnO}$ (0001) surface has been investigated [22-27]. Warschkow et al. [22] studied the stability of Cu-exposed ZnO (0001) surface structures in an oxygen environment using an ab initio atomistic thermodynamics method based on density functional theory (DFT), confirming that two structures with a $(\sqrt{3} \times \sqrt{3}) \mathrm{R} 30^{\circ}$ unit cell were prominently stable at intermediate oxygen and copper chemical potentials. Lyle et al. [23] studied the $\mathrm{Cu} / \mathrm{ZnO}$ (0001) surface with methanol via DFT calculations and found that more favorable energy was identified at higher coverage (1/4 ML versus 1/16 ML). Yang et al. [26] investigated Ag- and Au-adsorbed $\mathrm{ZnO}$ (0001) surfaces by first-principle calculations. And they found that Ag and Au atoms preferred to be adsorbed on the $\mathrm{H}_{3}$ sites of the surface, and Ag- and Au-adsorbed $\mathrm{ZnO}(0001)$ surfaces exhibited metal characteristics. Furthermore, Zhang et al. [27] investigated Si-adsorbed ZnO (0001) surface by first-principle calculations and observed that $\mathrm{H}_{3}$ sites played a critical role in the red shift of absorption edge. Iron (Fe), as an important transition metal element, also plays a key role in human life because it is abundant on earth (4.75\%), and iron-doped $\mathrm{ZnO}$ has shown better photocatalytic performance than that of intrinsic $\mathrm{ZnO}$, because an iron dopant generates a deep trap level at $E_{\mathrm{v}}+1.01 \mathrm{eV}$ in the band gap of $\mathrm{ZnO}$ [28]. However, the impact of iron atom adsorption on $\mathrm{ZnO}$ (0001) surface, to the best of our knowledge, has not been reported.

This paper presents a theoretical investigation of the effect of iron atom adsorption on the structural stability, electronic structure, and optical properties of a $\mathrm{ZnO}$ (0001) surface using first-principle computations. The surface work function of three adsorption sites on a $\mathrm{ZnO}(0001)$ surface is studied by electrostatic potential calculations. The photocatalytic performance of an iron-adsorbed $\mathrm{ZnO}$ (0001) surface is further discussed.

\section{Calculation Models and Methods}

All geometric structures in this work are calculated by the Cambridge Serial Total Energy Package (CASTEP) module of the Materials studio software on the basis of DFT [29,30]. The exchange-correlation energies are described by the generalized gradient approximation (GGA) with Perdew-Burke-Ernzerh (PBE) [31,32], and a plane-wave cutoff energy of $400 \mathrm{eV}$ is adopted. The valence-electron configurations are $\mathrm{Zn} 3 d^{10} 4 s^{2}, \mathrm{O} 2 s^{2} 2 p^{4}$, and Fe $3 d^{6} 4 s^{2}$. All systems are calculated in reciprocal space, and the Monkhorst-Pack grid of $(4 \times 4 \times 1)$ k-points is used. For the geometric structure relaxation, the energy 
charge and maximum tolerances of the force, stress, and displacement are set to $1 \times 10^{-5} \mathrm{eV} /$ atom, $0.03 \mathrm{eV} / \AA$, $0.05 \mathrm{GPa}$, and $0.001 \AA$, respectively.

On the basis of the optimized wurtzite $\mathrm{ZnO}$ unit cell, a cross-sectional plane of $\mathrm{ZnO}$ perpendicular to (0001) could be a Zn-rich (Zn-terminated) or O-rich (O-terminated) surface because bulk ZnO consists of $\mathrm{Zn}$ and O slabs alternatively along the (0001) direction [33]. As is shown in Figure 1, the Zn-terminated (0001) polar surface is constructed by a $(2 \times 2)$ surface unit cell slab geometry of periodically repeated supercells including five $\mathrm{Zn}-\mathrm{O}$ bilayers (10 atomic layers). The top three $\mathrm{Zn}-\mathrm{O}$ bilayers and the adatom layer are allowed to relax, while the two bottom $\mathrm{Zn}-\mathrm{O}$ bilayers are fixed to mimic the bulk structure. To eliminate the interaction between the two adjacent slabs, the surface supercells are separated from each other by the vacuum region, which is set to $15 \AA$ along the $z$-axis. The pseudo-hydrogens with a nuclear charge of $1 / 2$ for a $Z$ n-terminated surface are used to prevent the unphysical charge transfer between the top and bottom slabs. For an iron-adsorbed $\mathrm{ZnO}$ (0001) surface, three high-symmetry adsorption sites are considered: the $\mathrm{H}_{3}$ site with no atom beneath, the $\mathrm{T}_{4}$ site above a surface atom, and the Top site located at just above a surface atom.

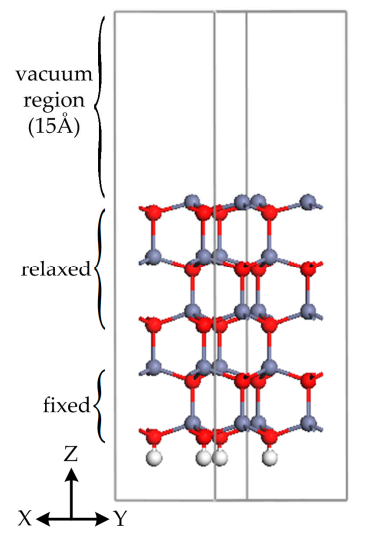

(a)

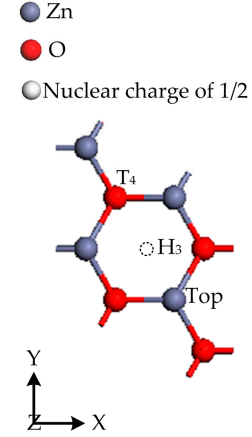

(b)

Figure 1. The side view (a) and top view (b) models of the pristine $(2 \times 2) \mathrm{ZnO}(0001)$ surface and three adsorption sites.

As is known, the adsorption energy per iron atom is calculated by the following formula [34]:

$$
E_{a}=E_{\text {tot }}-E_{\text {slab }}-\mu_{F e}
$$

where $E_{a}$ is the adsorption energy, $E_{\text {tot }}$ is the total energy of the surface system after iron adsorption, $E_{\text {slab }}$ is the energy of the clean $\mathrm{ZnO}(0001)$ surface, and $\mu_{F e}$ is the chemical potential of a single iron atom.

The surface work function $W_{f}$ is also a very significant property in the surface science, which is defined as the minimum energy required to remove an electron from the bulk of a material through a surface to a point in vacuum immediately outside the surface. In the calculation of the work function, the surface is assumed to be in its ground state both before and after removal of the electron [35]. In this work, under the conditions of a $0 \mathrm{~K}$ temperature and a perfect vacuum, the work function can be obtained as follows [36,37]:

$$
W_{f}=E_{v a c}-E_{f}
$$

where $E_{\text {vac }}$ is the converged electrostatic potential energy over the supercell slab surface, and the Fermi level energy $\left(E_{f}\right)$ is related to the highest occupied electronic state of the system.

To investigate the effect of iron adsorption on the photocatalytic properties of the $\mathrm{ZnO}(0001)$ surface, the optical properties are considered. Here, the calculated band gap of the bulk $\mathrm{ZnO}$, based on the GGA method, was $0.74 \mathrm{eV}$, which is smaller than the experimental value of $3.37 \mathrm{eV}$ [12]. As is known, the GGA method underestimates the band gap of transition metal oxides with a strong 
exchange correlation effect. Thus, spin-polarized GGA+U electronic structure calculations are adopted to accurately describe the electronic structure [38], and the Hubbard parameters $U_{d}$ for $\mathrm{Zn} 3 d$ states and $U_{p}$ for $\mathrm{O} 2 p$ states are considered to be 10 and $7 \mathrm{eV}[39,40]$, respectively. The calculated band gap (3.296 eV) of the bulk $\mathrm{ZnO}$ is in good agreement with the experimental value (3.37 eV). Additionally, the $U_{d}=2.5 \mathrm{eV}$ is added to Fe $3 d$ orbits in this work. Moreover, a dense $6 \times 6 \times 1 \mathrm{k}$-point mesh for the Brillouin zone is adopted in our optical performance calculation, and the optical properties are studied by the dielectric function of the frequency, which consists of the imaginary part $\varepsilon_{r}$ and the real part $\varepsilon_{i}$ :

$$
\varepsilon(\omega)=\varepsilon_{r}(\omega)+i \varepsilon_{i}(\omega)
$$

The imaginary part of the dielectric function $\varepsilon_{i}(\omega)$ is determined by a summation over empty band states [41]:

$$
\varepsilon_{i}(\omega)=\frac{2 \pi e^{2}}{\Omega \varepsilon_{0}} \sum_{k, v, c} \delta\left(E_{k}^{c}-E_{k}^{v}-\hbar \omega\right)\left|\left\langle\psi_{k}^{c}|u \cdot r| \psi_{k}^{v}\right\rangle\right|^{2}
$$

where $\omega$ is a given angular frequency of incident photons, $u$ is the vector defining the polarization of the incident electric field, $\Omega$ is the unit cell volume; $k$ is the reciprocal lattice vector, $v$ and $c$ denote the conduction and valence band states, respectively, and $\psi_{k}^{c}$ and $\psi_{k}^{v}$ are the wave functions of the conduction and valence bands, respectively. The real part $\varepsilon_{r}(\omega)$ can be calculated from $\varepsilon_{i}(\omega)$ using the Kramers-Kronig relations [42] as follows:

$$
\varepsilon_{r}(\omega)=1+\frac{2}{\pi} \int_{0}^{\infty} \frac{\omega^{\prime} \varepsilon_{i}\left(\omega^{\prime}\right)}{\left(\omega^{\prime 2}-\omega^{2}\right)} d \omega^{\prime}
$$

Then, the other optical constants can be obtained from $\varepsilon_{r}(\omega)$ and $\varepsilon_{i}(\omega)$, such as the absorption coefficient $\alpha(\omega)$, which can be expressed as [43]:

$$
\alpha(\omega)=\sqrt{2} \omega\left[\sqrt{\varepsilon_{r}^{2}(\omega)+\varepsilon_{i}^{2}(\omega)}-\varepsilon_{r}(\omega)\right]^{1 / 2} .
$$

\section{Results and Discussion}

\subsection{Geometries and Structural Stability}

Table 1 summarizes the obtained lattice constants of bulk wurtzite $\mathrm{ZnO}$ unit cell, which matches well with previous investigation results, thereby confirming the correctness of our calculation. Figure 2 shows the geometric structures of the bulk $\mathrm{ZnO}$ and the pristine $\mathrm{ZnO}$ (0001) surface. Figure 2a,b show that both the spacings of $\mathrm{Zn}$ and $\mathrm{O}$ atoms in the same $\mathrm{Zn}-\mathrm{O}$ bilayer and the distances between the zinc atomic planes of the relaxed $\mathrm{Zn}-\mathrm{O}$ bilayers of $\mathrm{ZnO}$ (0001) surface are all smaller than those of the bulk $\mathrm{ZnO}$, respectively, which is due to the compression at the relaxed layers, and this phenomenon is confirmed by Ag- or Au-adsorbed ZnO (0001) surfaces [26]. Meanwhile, the smaller the spacing and distance of the outer bilayers are, the weaker the lattice constraint is at the relaxed surface.

Table 1. Calculated and experimental values of the structural parameters for bulk $\mathrm{ZnO}$ unit cell. a, b, and $c$ are the lattice parameters.

\begin{tabular}{cccc}
\hline Lattice Constants & Present Work & Previous Computation ${ }^{\mathbf{i}}$ & Experiment $^{\text {ii }}$ \\
\hline a $(\AA)$ & 3.2820 & 3.2935 & 3.250 \\
b $(\AA)$ & 3.2820 & 3.2935 & 3.250 \\
c $(\AA)$ & 5.2951 & 5.2877 & 5.201 \\
c/a & 1.6134 & 1.6050 & 1.600 \\
\hline \multicolumn{4}{c}{}
\end{tabular}




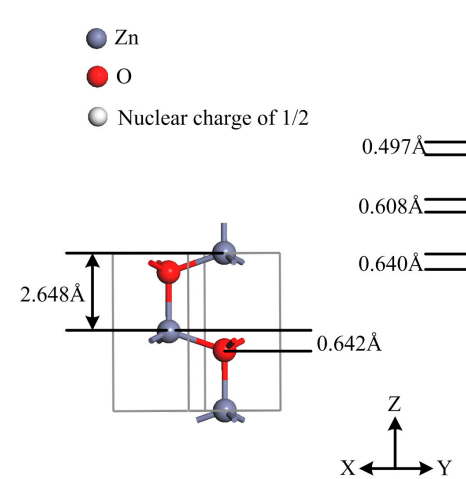

(a)

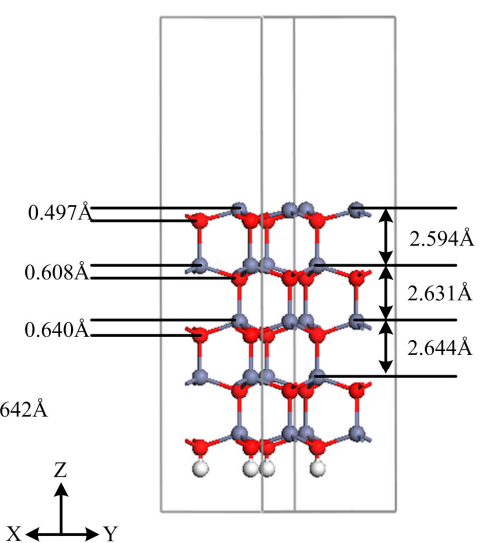

(b)

Figure 2. Schematic models of $(\mathbf{a})$ the bulk wurtzite $\mathrm{ZnO}$ unit cell and $(\mathbf{b})$ the pristine $(2 \times 2)(0001)$ surface.

Figure 3 shows the geometric structures of $\mathrm{ZnO}$ (0001) surface with three high symmetry iron adsorption sites. As is observed, the iron atoms have a significant impact on the adjacent zinc and oxygen atoms. Table 2 lists the total energy, bond length, and adsorption energy of the iron adatoms for these three sites. It can be found that, after the geometrical optimization, when the iron atoms are adsorbed on $\mathrm{H}_{3}$ and $\mathrm{T}_{4}$ sites, each iron adatom will have three neighboring zinc atoms within the distances of 2.482 and $2.318 \AA$, respectively. The iron atom adsorbed at $\mathrm{T}_{4}$ will form a bond with the oxygen atom just below the site, with a bond length of $1.703 \AA$. At the Top site, the iron atom will attract one zinc atom from the surface within a distance of $2.339 \AA$. Based on the surface adsorption energy calculation, all of the adsorption sites can be easily adsorbed on the $\mathrm{ZnO}(0001)$ surface. This is because the surface adsorption energy of these three sites is negative and small, so the adhesion of the iron atom on the $\mathrm{ZnO}$ (0001) surface is easier and the iron-adsorbed $\mathrm{ZnO}$ surface will be quite stable. Specifically, the $\mathrm{H}_{3}$ site has the lowest adsorption energy of $-5.665 \mathrm{eV}$, so the adsorption of iron adatom on the $\mathrm{H}_{3}$ site is the most favorable compared with the other two sites, and this result is consistent with the former reports in $[33,46]$.
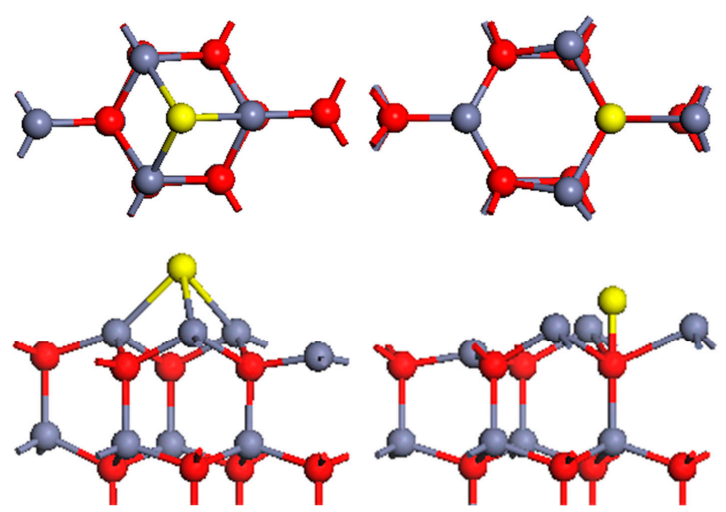

(a)

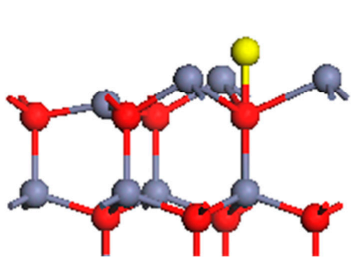

(b)

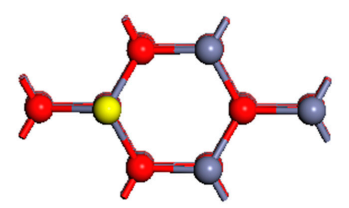

O Zn

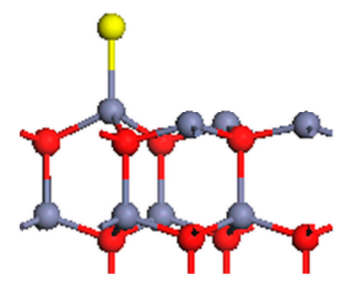

(c)

Figure 3. The side and top view of the optimized structures of iron atom adsorbed on (a) the $\mathrm{H}_{3}$ site; (b) the $\mathrm{T}_{4}$ site; (c) the Top site of $\mathrm{ZnO}$ (0001) surface. 
Table 2. The total energy, bond length, and adsorption energy (eV) of the iron-adsorbed $\mathrm{ZnO}$ (0001) surface.

\begin{tabular}{ccccc}
\hline \multirow{2}{*}{ Fe-Adsorbed Site } & \multirow{2}{*}{$\boldsymbol{E}_{\text {total }}(\mathbf{e V})$} & \multicolumn{2}{c}{ Bond Length $(\AA)$} & \multirow{2}{*}{$\boldsymbol{E}_{\boldsymbol{a}}(\mathbf{e V})$} \\
\cline { 3 - 4 } & & Fe-O & Fe-Zn & \\
\hline $\mathrm{H}_{3}$ & $-43,845.903$ & - & 2.482 & -5.665 \\
$\mathrm{~T}_{4}$ & $-43,844.674$ & 1.703 & 2.318 & -4.436 \\
Top & $-43,845.403$ & - & 2.339 & -5.165 \\
Clean surface & $-42,984.348$ & - & - & - \\
\hline
\end{tabular}

\subsection{Electronic Structure}

Figure 4 presents the computed spin-polarized band structures of the pristine and iron-adsorbed $\mathrm{ZnO}$ (0001) surfaces via the GGA+U approach. The Fermi level is set as zero in the energy level. As can be seen in Figure 4a, the calculated band structure of the pristine $\mathrm{ZnO}$ (0001) surface exhibits a direct band gap because the conduction band minimum (CBM) and the valence band maximum (VBM) are situated at the same $\Gamma$ point of the Brillouin zone. The achieved band gap of the pristine $\mathrm{ZnO}(0001)$ surface is $2.67 \mathrm{eV}$, which is smaller than that of the intrinsic bulk $\mathrm{ZnO}$ counterpart (about $3.296 \mathrm{eV}$ ) due to the occurrence of the surface state band in the bulk band gap and the electric field in the slab induced by band bending $[21,47,48]$. In addition, the Fermi level shifts the conduction band (CB) upward, and the quantum states near the CBM are then occupied by electrons, indicating that the $\mathrm{ZnO}$ (0001) surface is an n-type degenerate semiconductor with metallic characteristics. This is mainly because the shallow donor states are created in the bottom of the $C B$, inducing an increase in the carrier concentration. Figure $4 \mathrm{~b}-\mathrm{d}$ demonstrate the band structures of the iron-adsorbed $\mathrm{ZnO}(0001)$ surfaces. It can be observed that they are similar to that of the pristine $\mathrm{ZnO}(0001)$ surface. The band structure shows a direct gap at the $\Gamma$ point when the iron atom is adsorbed on the $\mathrm{ZnO}$ (0001) surface, and the Fermi level of both spin-up and spin-down channels also lie in the CB. It is worth mentioning that the band gaps in the spin-up and spin-down channels of all adsorbed $\mathrm{ZnO}$ surface systems are smaller than those of the pristine $\mathrm{ZnO}$ (0001) surface (2.67 eV). Specifically, in Figure $4 \mathrm{~b}$, d showing the band structures in the spin-up channel of the $\mathrm{H}_{3}$ and Top configurations, the impurity levels $\left(E_{r}\right)$ located at -2.91 and $-2.38 \mathrm{eV}$ are created in the forbidden band at the $\Gamma$ point, respectively, and the $E_{r}$ may become effective recombination centers. Figure $4 \mathrm{c}$ shows the band structure of $\mathrm{T}_{4}$ configuration. It is found that the iron adatom does not produce an obvious $E_{r}$, whereas the band gaps in both spin channels significantly decrease to 1.213 and $1.333 \mathrm{eV}$, respectively. Notably, there are several Fe-related levels near the Fermi level of these two spin channels and the upper part of the VB in the spin-up channel. Furthermore, under the irradiation of the solar spectrum, because of the impact of the Fe-related level on the vicinity to the Fermi level, the Fermi level will function as a "springboard" for electrons to jump into the CB, which may lead to a stronger optical absorption coefficient in the visible light region [15].

The calculated total density of state (TDOS) and the projected density of state (PDOS) of these two spin channels for the pristine and iron-adsorbed $\mathrm{ZnO}$ (0001) surfaces are presented in Figure 5, respectively. As is shown in Figure 5a, the CB of the pristine $\mathrm{ZnO}$ (0001) surface mainly consists of $\mathrm{Zn}-4 s$ and O-2 $p$ states, and the VB is mainly composed of $\mathrm{Zn}-3 d$ and O-2 $p$ states. In addition, the spin-up and spin-down components of the TDOS and PDOS are symmetrical, implying that the pristine $\mathrm{ZnO}$ (0001) surface is nonmagnetic, whereas the iron-adsorbed $\mathrm{ZnO}$ (0001) surfaces, based on Figure 5b-d, are magnetic due to the fact that the iron element belongs to the transition metal element and that the TDOS of these two spin channels near the Fermi level are asymmetrical. Compared with the pristine $\mathrm{ZnO}$ (0001) surface in Figure 5a, the Fe-3d states mainly have contribution to the CB in the spin-down channel near the Fermi level and the upper part of the VB in the two spin channels of all the iron-adsorbed $\mathrm{ZnO}$ surfaces. Moreover, in the $\mathrm{CB}$ with a range from 1 to $4 \mathrm{eV}$, all the Fe- $3 d$ states exhibit strong localization, making the $\mathrm{CB}$ of iron-adsorbed $\mathrm{ZnO}$ (0001) surface more intensive. However, in 
the upper part of the VB with a range from -5 to $-3 \mathrm{eV}$, there is strong hybridization between the $\mathrm{Fe}-3 d$ and $\mathrm{O}-2 p$ states, implying the strong interaction between iron and oxygen atoms. Moreover, from Figure $5 b, d$, it can be seen that Fe-4s states exhibit localization near the -2.72 and $-2.15 \mathrm{eV}$, respectively, which matches with the results in Figure $4 \mathrm{~b}, \mathrm{~d}$. In particular, it should be noted that, in Figure $5 c$, there is a stronger interaction between Fe-3d and O- $2 p$ states in the upper part of the VB of the $\mathrm{T}_{4}$ site compared with the $\mathrm{H}_{3}$ and Top configurations, which further confirms the bond between iron adatom and the surface oxygen atom of the first bilayer in Table 2.

Figure 6 presents the calculated electrostatic potential of the pristine and iron-adsorbed $\mathrm{ZnO}(0001)$ surface systems. The adsorption of iron atom on the $\mathrm{ZnO}$ (0001) surface will affect the surface work function that can be achieved by averaging the electrostatic potential along the $z$-axis [35]. Figure 6a gives the electrostatic potential of the pristine $\mathrm{ZnO}$ (0001) surface, which tends to be flat in the vacuum region because of the introduction of pseudo-hydrogens, and this result is consistent with previous work [36]. In Figure $6 \mathrm{~b}-\mathrm{d}$, iron atom adsorbed on the $\mathrm{T}_{4}$ site will increase the work function of the $\mathrm{ZnO}$ (0001) surface, which is the opposite of the scenarios of the $\mathrm{H}_{3}$ and Top adsorption sites. Moreover, compared with the pristine $\mathrm{ZnO}$ (0001) surface, the work function of the Top configuration decreases to $1.768 \mathrm{eV}$ and declines most among the three sites. According to Qiao et al. [49,50], the surface work function is sensitive to the charge transfer and surface state concentration. Thus, the variation of the surface work function may be ascribed to the fact that iron adatom is bonded to the oxygen atom in the topmost layer when iron atom is adsorbed on the $\mathrm{T}_{4}$ site, and iron adatom will interact with zinc atoms when iron atom is adsorbed on the $\mathrm{H}_{3}$ and Top sites. This may lead to the changes of chemical properties and surface states in the (0001) surface. Accordingly, the photocatalytic reaction rate will be promoted.

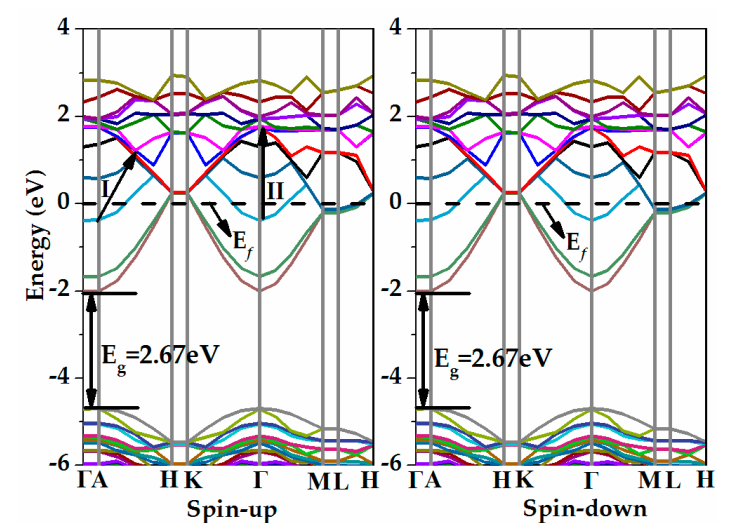

(a)

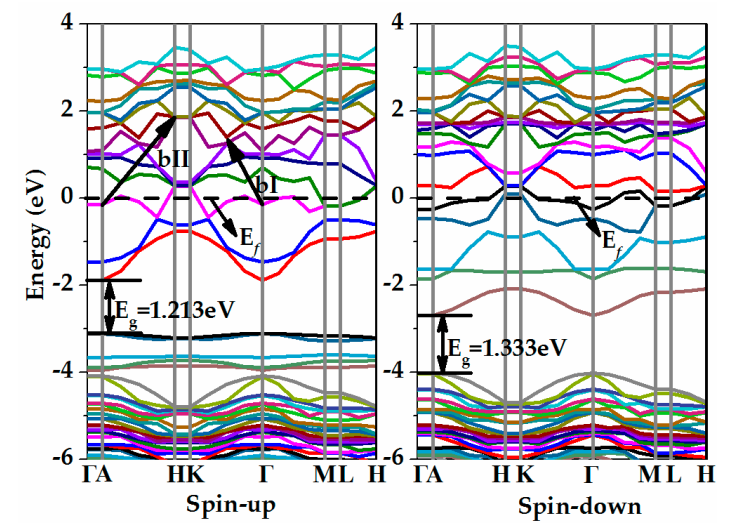

(c)

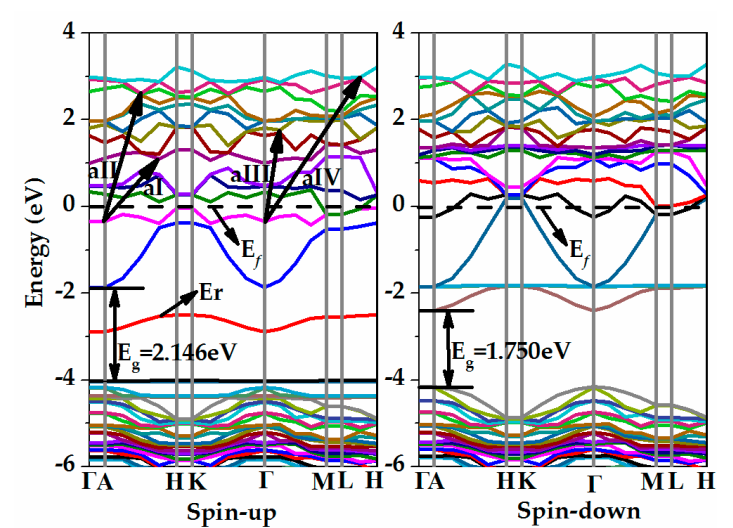

(b)

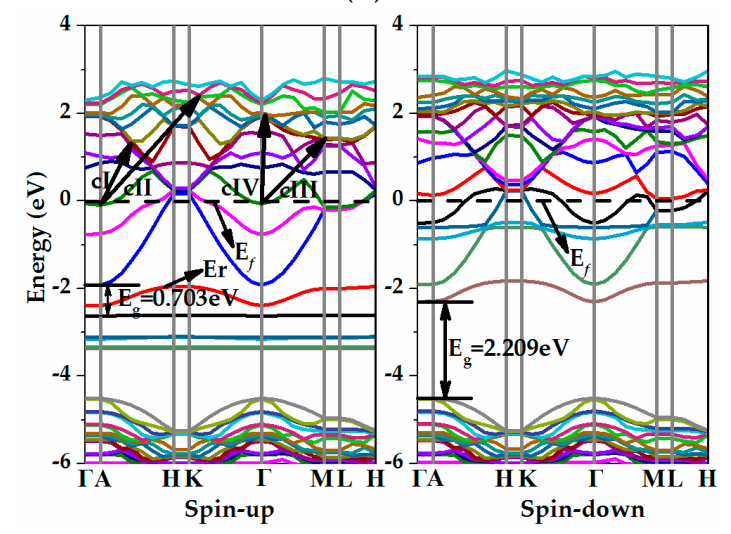

(d)

Figure 4. The band structures of (a) pristine $\mathrm{ZnO}(0001)$ and iron atom adsorbed on (b) the $\mathrm{H}_{3}$ site, (c) the $\mathrm{T}_{4}$ site, and (d) the Top site of the $\mathrm{ZnO}$ (0001) surface via the GGA+U method. 


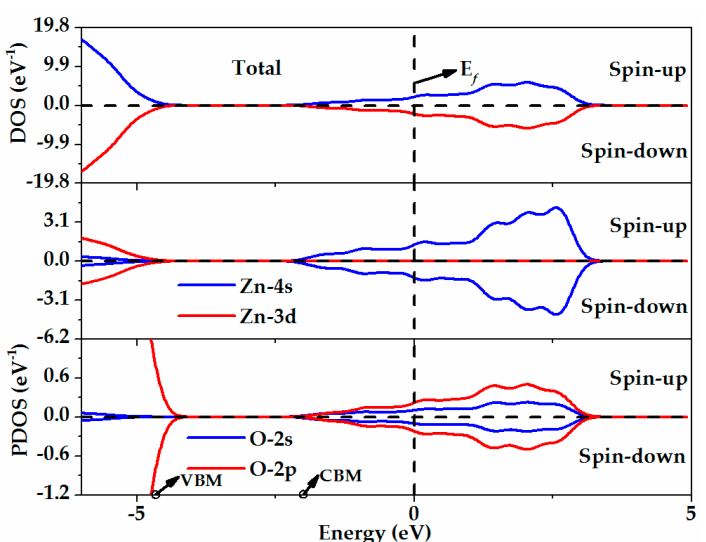

(a)

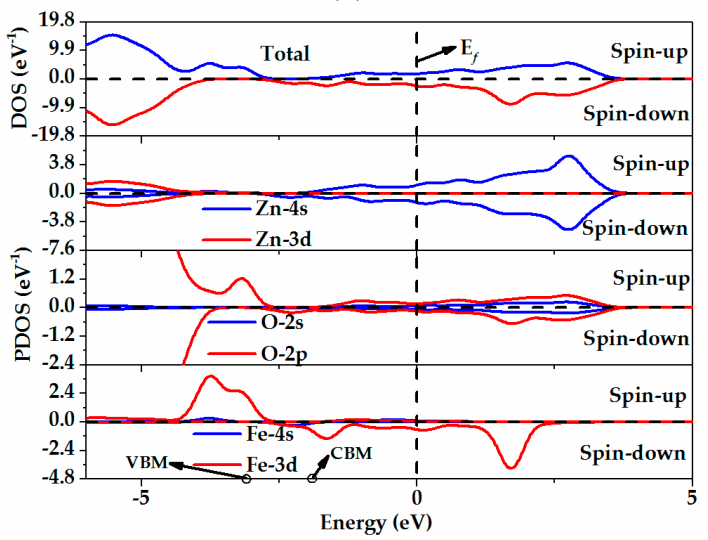

(c)

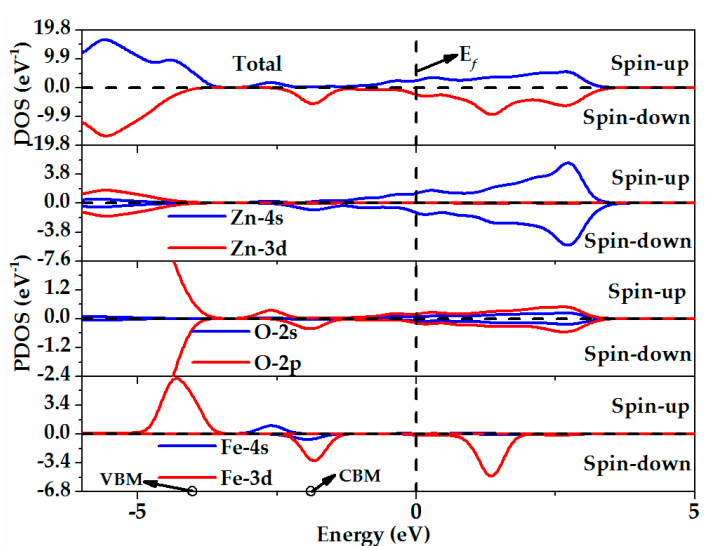

(b)

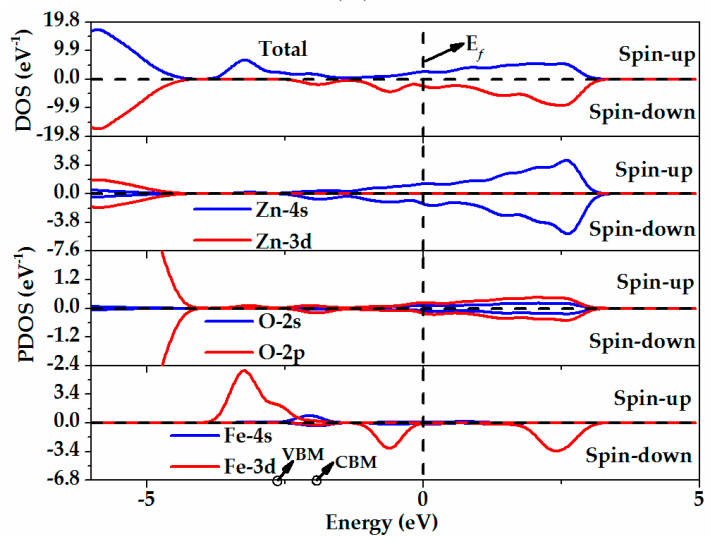

(d)

Figure 5. The total density of state (TDOS) and the projected density of state (PDOS) of (a) the pristine $\mathrm{ZnO}(0001)$ and the iron atom adsorbed on (b) the $\mathrm{H}_{3}$ site, (c) the $\mathrm{T}_{4}$ site, and (d) the Top site of $\mathrm{ZnO}$ (0001) surface via the GGA+U method. The positions of the conduction band minimum (CBM) and the valence band maximum (VBM) are also denoted.

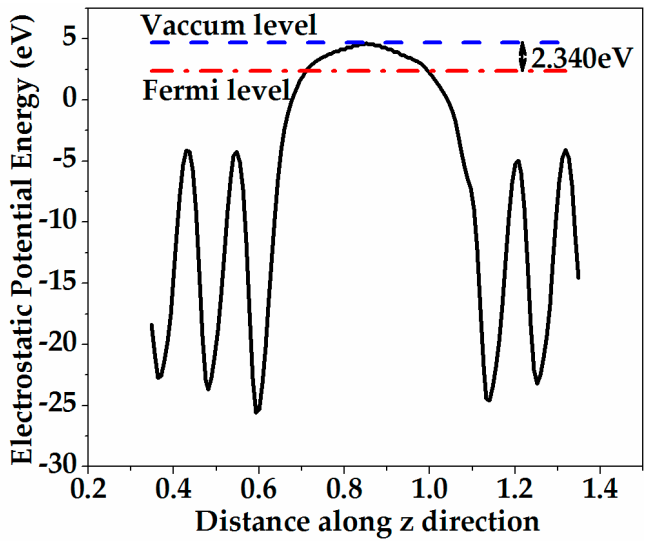

(a)

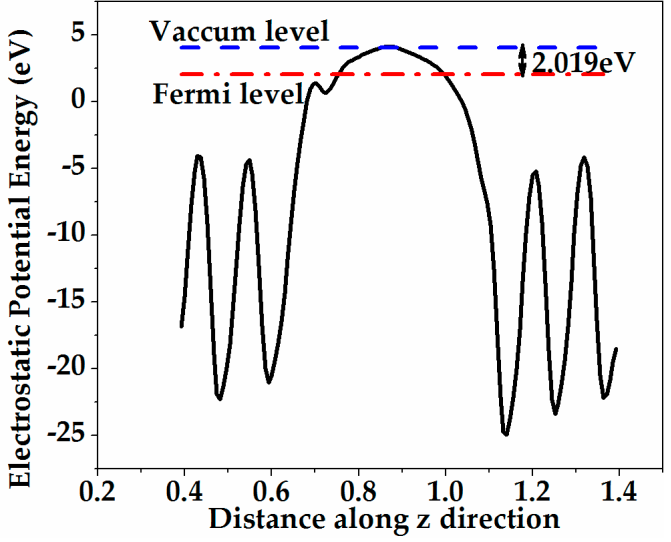

(b)

Figure 6. Cont. 


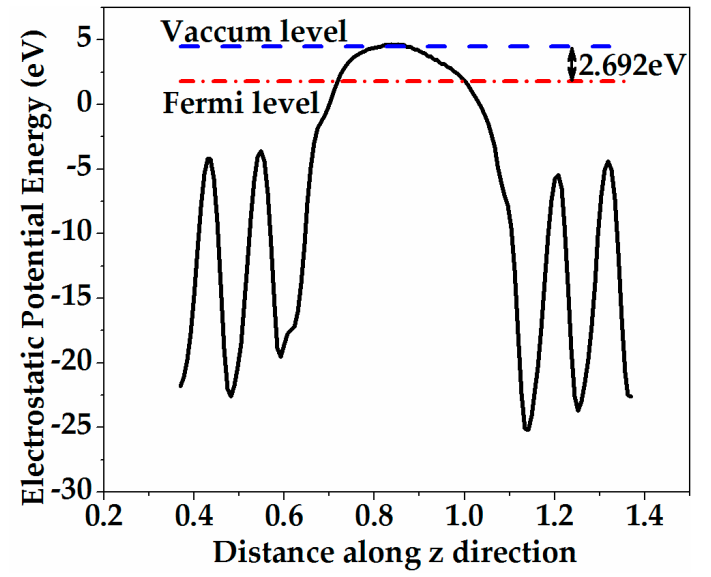

(c)

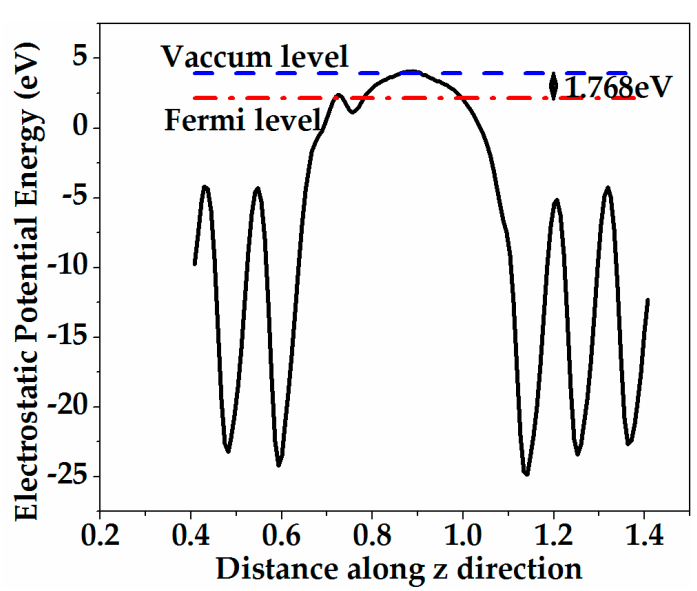

(d)

Figure 6. Calculated electrostatic potential of the $z$ direction for (a) the pristine $\mathrm{ZnO}(0001)$ surface and the iron atom adsorbed on (b) the $\mathrm{H}_{3}$ site, (c) the $\mathrm{T}_{4}$ site, and (d) the Top site of the $\mathrm{ZnO}(0001)$ surface.

\subsection{Optical Properties}

Figure 7 plots the calculated spectra of absorption coefficient $(\alpha)$ for the pristine and iron-adsorbed $\mathrm{ZnO}$ (0001) surfaces. The incident radiation has linear polarization along the (100) and (001) directions. As can be seen, compared with the pristine $\mathrm{ZnO}$ (0001) surface, the absorption coefficient of the iron-adsorbed $\mathrm{ZnO}$ (0001) surface is steeply increased in the visible and infrared (IR) regions along the (100) direction and enhanced in the near-ultraviolet light region along the (001) direction. Meanwhile, the iron atom adsorbed on the Top adsorption site has the highest adsorption coefficient in the region from 0 to $2.6 \mathrm{eV}$ along the (100) direction, and $\mathrm{H}_{3}$ configuration has the highest adsorption coefficient in the range from 3.5 to $5.2 \mathrm{eV}$ along the (001) direction. Such enhanced visible light absorption in the iron-adsorbed $\mathrm{ZnO}$ (0001) surface may be attributed to the narrow band gaps and the Fe-related levels near the Fermi level. For the scenario of the iron atom adsorbed on the $\mathrm{H}_{3}$ and Top sites, as shown in Figure $4 b$,d, there are obvious Fe-related levels located in the forbidden band with smaller energy gaps of 2.146 and $0.703 \mathrm{eV}$, which may induce more electronic transitions and thus enhance the optical absorption coefficient. However, for the iron atom adsorbed on the $T_{4}$ site in Figure $4 c$, the introduced Fe-related levels at the upper part of the VB in the spin-up channel make the band gap smaller than that of the pristine $\mathrm{ZnO}$ (0001) surface, therefore improving the absorption coefficient in the visible light region. Table 3 shows the relationship between the transition process (please refer to Figure 4) and the position of adsorption peaks. For the n-type degenerate semiconductors, the Fermi levels will enter into the $C B$, and the quantum states between the CBM and Fermi level will be occupied by electrons [51]. Thus, the absorption peak is mainly affected by the band gap and the intraband transition of hot electrons. It can be found in Table 3 that the prominent absorption peak in the low energy region of the pristine $\mathrm{ZnO}$ (0001) surface is located at $1.72 \mathrm{eV}$ along the (100) direction, which coincides well with data $(1.76 \mathrm{eV})$ in [27]. Compared with it, the absorption peak in the lower-energy region of the $\mathrm{H}_{3}$ site is observed at $1.12 \mathrm{eV}$ with a clear red shift. The absorption peak of the $\mathrm{T}_{4}$ site is also located at $1.72 \mathrm{eV}$, whereas the light adsorption is elevated in both the visible light and the near-ultraviolet light regions. Moreover, at the Top site, the absorption peak shifts toward the lower-energy region, but the absorption intensity is strengthened significantly. This is because the compounds adsorbed by the iron atom on the $\mathrm{ZnO}(0001)$ surface are all n-type degenerate materials and the absorption peaks are from the intraband transitions of hot electrons. 


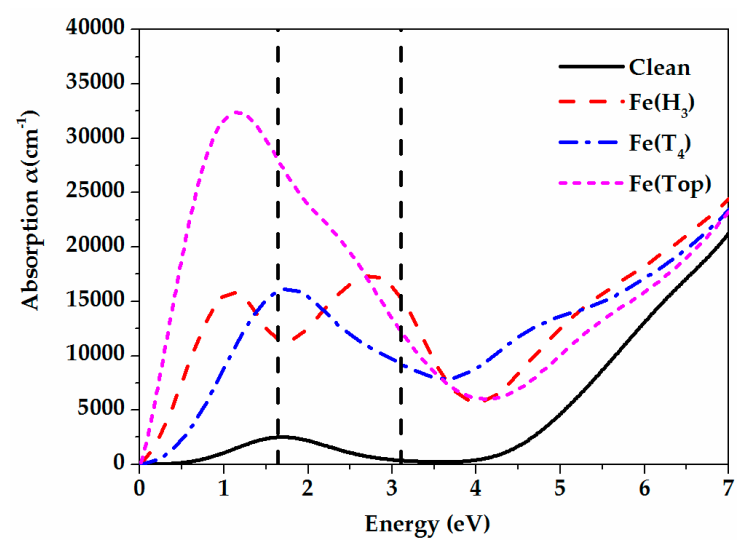

(a)

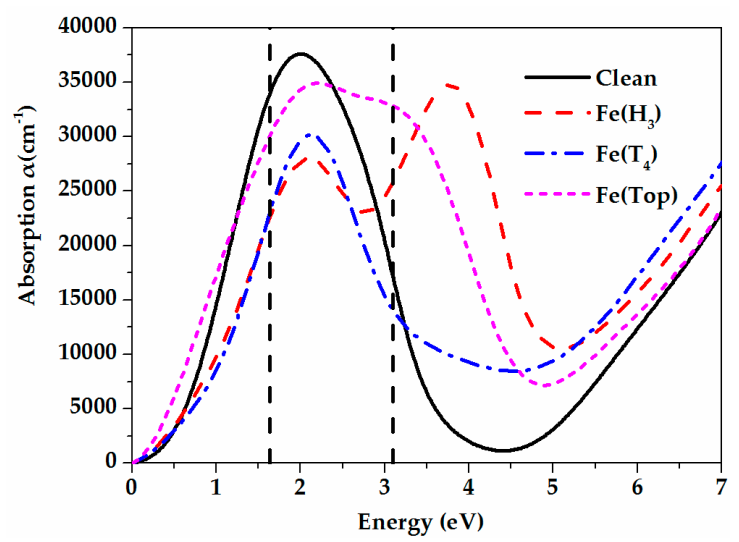

(b)

Figure 7. The calculated optical absorption spectra of the pristine and iron-adsorbed $\mathrm{ZnO}(0001)$ surfaces along the (a) (100) and (b) (001) directions. Vertical dash lines represent the energy range of visible light spectrum (i.e., $1.64-3.10 \mathrm{eV}$ correspond to $760-400 \mathrm{~nm}$ ).

Table 3. The position of adsorption peaks of the iron-adsorbed $\mathrm{ZnO}(0001)$ surface along the (100) and (001) directions and the corresponding transition process.

\begin{tabular}{|c|c|c|c|c|c|c|c|c|}
\hline \multirow{2}{*}{ Direction } & \multicolumn{2}{|c|}{ Clean Surface } & \multicolumn{2}{|c|}{$\mathrm{Fe}\left(\mathrm{H}_{3}\right)$} & \multicolumn{2}{|c|}{$\mathrm{Fe}\left(\mathrm{T}_{4}\right)$} & \multicolumn{2}{|c|}{ Fe(Top) } \\
\hline & Position (eV) & Process & Position (eV) & Process & Position (eV) & Process & Position (eV) & Process \\
\hline \multirow{2}{*}{ (100) } & \multirow{2}{*}{1.72} & \multirow{2}{*}{ I } & 1.12 & aI & \multirow{2}{*}{1.72} & \multirow{2}{*}{ bI } & 1.17 & cI \\
\hline & & & 2.75 & aII & & & 2.30 & cII \\
\hline \multirow{2}{*}{ (001) } & \multirow{2}{*}{1.92} & \multirow{2}{*}{ II } & 2.11 & aIII & \multirow{2}{*}{2.12} & \multirow{2}{*}{ bII } & 2.28 & cIII \\
\hline & & & 3.77 & aIV & & & 2.96 & cIV \\
\hline
\end{tabular}

\subsection{Photocatalytic Performance}

Figure 8 presents the possible photocatalytic reaction mechanism of iron-adsorbed $\mathrm{ZnO}(0001)$ surface under visible light irradiation. As can be seen, when the iron-adsorbed ZnO (0001) surface is confronted with solar light irradiation, the photoinduced electrons transfer from the $\mathrm{ZnO}$ (0001) surface to the iron atoms. At the same time, the photogenerated holes remain on the surface and the photogenerated electron-hole pairs are separated with a recombination reduction [1], thus enhancing the photocatalytic activity and the degradation rate of the iron-adsorbed $\mathrm{ZnO}$ (0001) surface.

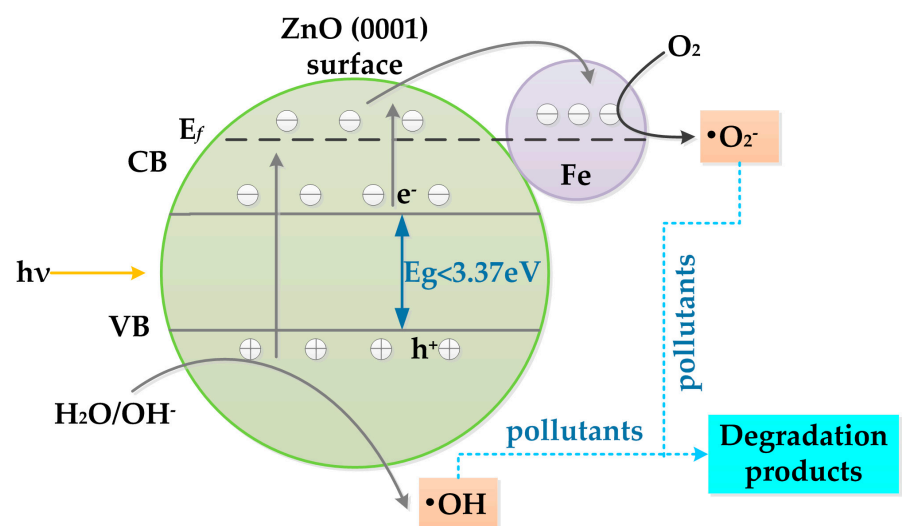

Figure 8. Schematic explanation of the transfer of electron-hole pairs in iron-adsorbed $\mathrm{ZnO}$ (0001) surface leading to the degradation of pollutants under sunlight irradiation. 
During the decomposition process, the photoexcited electrons will react with $\mathrm{O}_{2}$ forming superoxide radical anions $\left(\cdot \mathrm{O}_{2}^{-}\right)$and the photoinduced holes will react with $\mathrm{H}_{2} \mathrm{O}$ or $\mathrm{OH}^{-}$to produce hydroxyl radicals $(\cdot \mathrm{OH})$, which can be utilized as species for the degradation of organic pollutants by oxidation [52]. According to the formation process of $\mathrm{e}^{-} / \mathrm{h}^{+}$pairs, as shown in Figure 8 , the possible mechanism of the iron-adsorbed $\mathrm{ZnO}$ (0001) surface photocatalyst for the degradation of pollutants can be proposed as follows:

$$
\begin{gathered}
\text { Fe-ZnO (0001) surface }+\mathrm{h} v \rightarrow \mathrm{e}^{-}+\mathrm{h}^{+} \\
\mathrm{H}_{2} \mathrm{O} / \mathrm{OH}^{-}+\mathrm{h}^{+} \rightarrow \cdot \mathrm{OH} \\
\mathrm{O}_{2}+\mathrm{e}^{-} \rightarrow \cdot \mathrm{O}_{2}^{-} / \cdot 2 \mathrm{O}^{-} \\
\mathrm{h}^{+}+\cdot \mathrm{O}_{2}^{-} / \cdot 2 \mathrm{O}^{-}+\cdot \mathrm{OH}+\text { pollutant } \rightarrow \mathrm{CO}_{2}+\mathrm{H}_{2} \mathrm{O}
\end{gathered}
$$

From the above photocatalytic process, it can be found that the photocatalytic activity of iron-adsorbed $\mathrm{ZnO}$ (0001) surface will be higher than that of the pristine $\mathrm{ZnO}$ (0001) surface. This is mainly because the adsorption of iron atom will promote the separation between the electrons and holes, thus prolonging the charge carrier lifetime. Subsequently, more carriers separated will move to the $\mathrm{ZnO}$ (0001) surface and participate in the redox reactions under irradiation with visible light. Finally, the organic pollutants are decomposed to the non-toxic $\mathrm{CO}_{2}$ and $\mathrm{H}_{2} \mathrm{O}$.

\section{Conclusions}

The impact of iron adsorption on the structural stability, electronic structure, and optical properties of the pristine and iron-doped $\mathrm{ZnO}(0001)$ surface were studied via first-principle computations with the GGA+U method. The results show that the spacings between $\mathrm{Zn}$ and $\mathrm{O}$ atoms in the same $\mathrm{Zn}-\mathrm{O}$ bilayer and the distances between the zinc atomic planes of different relaxed $\mathrm{Zn}-\mathrm{O}$ bilayers of $\mathrm{ZnO}$ (0001) surface are shrunk. Iron atoms prefer to be adsorbed on the $\mathrm{H}_{3}$ site of $\mathrm{ZnO}$ (0001) surface with a low adsorption energy of about $-5.665 \mathrm{eV}$. The band gap of the iron-adsorbed $\mathrm{ZnO}(0001)$ surface is lower than that of the pristine $\mathrm{ZnO}$ (0001) surface. Particularly, the Fe-related levels are located at the forbidden band and near the Fermi level for the case of iron adsorption on the $\mathrm{H}_{3}$ and Top sites, whereas, for the $\mathrm{T}_{4}$ site, the Fe-related levels are located at the upper part of the $\mathrm{VB}$ and near the Fermi level, inducing more electronic transitions and a significant improvement of the optical absorption coefficient in the visible light energy region. Furthermore, besides the $\mathrm{T}_{4}$ site, the work function of the $\mathrm{H}_{3}$ and Top sites is also decreased. This work can provide reference for the investigation of the photocatalytic properties of the $\mathrm{ZnO}$ (0001) polar surface.

Acknowledgments: This work was supported by the National Natural Science Foundation of China (Grant No. 61474090), by the Key Research and Development Program of Shaanxi Province of China (Grant No. 2017ZDXM-GY-052), and partly by the 111 Project of China (B08038).

Author Contributions: Jingsi Cheng performed the calculations; Ping Wang designed the project; Jingsi Cheng, Ping Wang, Chao Hua, Yintang Yang, and Zhiyong Zhang analyzed the results; Jingsi Cheng and Ping Wang wrote the manuscript.

Conflicts of Interest: The authors declare no conflict of interests.

\section{References}

1. Muñoz-Fernandez, L.; Sierra-Fernandez, A.; Milošević, O. Solvothermal synthesis of Ag/ZnO and Pt/ZnO nanocomposites and comparison of their photocatalytic behaviors on dyes degradation. Adv. Powder Technol. 2016, 27, 983-993. [CrossRef]

2. Wu, M.C.; Wu, P.Y; Lin, T.H. Photocatalytic Performance of Cu-doped $\mathrm{TiO}_{2}$ Nanofibers Treated by the Hydrothermal Synthesis and Air-thermal Treatment. Appl. Surf. Sci. 2017, 430, 390-398. [CrossRef]

3. Moradi, V.; Jun, M.B.G.; Blackburn, A.; Herring, R.A. Significant improvement in visible light photocatalytic activity of Fe doped $\mathrm{TiO}_{2}$ using an acid treatment process. Appl. Surf. Sci. 2017, 427, 791-799. [CrossRef] 
4. Nunes, D.; Pimentel, A.; Santos, L.; Barquinha, P.; Fortunato, E.; Martins, R. Photocatalytic $\mathrm{TiO}_{2} \mathrm{Nanorod}$ Spheres and Arrays Compatible with Flexible Applications. Catalysts 2017, 7, 60. [CrossRef]

5. Su, Y.; Ao, D.; Liu, H.; Wang, Y. MOF-derived yolk-shell CdS microcubes with enhanced visible-light photocatalytic activity and stability for hydrogen evolution. J. Mater. Chem. A 2017, 5, 8680-8689. [CrossRef]

6. Garg, P.; Kumar, S.; Choudhuri, I.; Mahata, A.; Pathak, B. Hexagonal Planar CdS Monolayer Sheet for Visible Light Photocatalysis. J. Phys. Chem. C 2016, 120, 7052-7060. [CrossRef]

7. Tabib, A.; Bouslama, W.; Sieber, B.; Addad, A.; Elhouichet, H.; Férid, M.; Boukherroub, R. Structural and optical properties of Na doped ZnO nanocrystals: Application to solar photocatalysis. Appl. Surf. Sci. 2017, 396, 1528-1538. [CrossRef]

8. Cheng, Y.F.; Jiao, W.; Li, Q.; Zhang, Y.; Li, S.; Li, D.; Che, R. Two hybrid Au-ZnO aggregates with different hierarchical structures: A comparable study in photocatalysis. J. Colloid Interface Sci. 2018, 509, 58-67. [CrossRef] [PubMed]

9. Bai, S.; Liu, H.; Sun, J.; Tian, Y.; Chen, S.; Song, J.; Luo, R.; Li, D.; Chen, A.; Liu, C.C. Improvement of TiO photocatalytic properties under visible light by $\mathrm{WO}_{3} / \mathrm{TiO}_{2}$ and $\mathrm{MoO}_{3} / \mathrm{TiO}_{2}$ composites. Appl. Surf. Sci. 2015, 338, 61-68. [CrossRef]

10. Arfaoui, A.; Touihri, S.; Mhamdi, A.; Labidi, A.; Manoubi, T. Structural, morphological, gas sensing and photocatalytic characterization of $\mathrm{MoO}_{3}$ and $\mathrm{WO}_{3}$ thin films prepared by the thermal vacuum evaporation technique. Appl. Surf. Sci. 2015, 357, 1089-1096. [CrossRef]

11. Raji, R.; Sibi, K.S.; Gopchandran, K.G. ZnO:Ag nanorods as efficient photocatalyst: Sunlight driven photocatalytic degradation of sulforhodamine B. Appl. Surf. Sci. 2018, 427, 863-875. [CrossRef]

12. Jiang, X.H.; Shi, J.J.; Zhang, M.; Zhong, H.X.; Huang, P.; Ding, Y.M.; Cao, X.; Wu, M. Modulation of electronic and optical properties of $\mathrm{ZnO}$ by inserting an ultrathin $\mathrm{ZnX}(\mathrm{X}=\mathrm{S}$, Se and $\mathrm{Te}$ ) layer to form short-period $(\mathrm{ZnO})_{5} /(\mathrm{ZnX})_{1}$ superlattice. J. Alloys Compd. 2017, 711, 581-591. [CrossRef]

13. Razavi-Khosroshahi, H.; Edalati, K.; Wu, J.; Nakashima, Y.; Arita, M.; Ikoma, Y.; Sadakiyo, M.; Inagaki, Y.; Staykov, A.; Yamauchi, M.; et al. High-pressure zinc oxide phase as visible-light-active photocatalyst with narrow band gap. J. Mater. Chem. A 2017, 5, 20298-20303. [CrossRef]

14. Bhatia, S.; Verma, N.; Bedi, R.K. Sn-doped ZnO Nanopetal networks for Efficient Photocatalytic Degradation of dye and Gas Sensing Applications. Appl. Surf. Sci. 2017, 407, 495-502. [CrossRef]

15. Yu, W.; Zhang, J.; Peng, T. New insight into the enhanced photocatalytic activity of N-, C-and S-doped ZnO photocatalysts. Appl. Catal. B-Environ. 2016, 181, 220-227. [CrossRef]

16. Li, W.; Wang, G.; Feng, Y.; Li, Z. Efficient photocatalytic performance enhancement in Co-doped ZnO nanowires coupled with CuS nanoparticles. Appl. Surf. Sci. 2017, 428, 154-164. [CrossRef]

17. Harish, S.; Sabarinathan, M.; Archana, J.; Navaneethan, M.; Nisha, K.D.; Ponnusamy, S.; Gupta, V.; Muthamizhchelvan, C.; Aswal, D.K.; Ikeda, H.; et al. Synthesis of ZnO/SrO nanocomposites for enhanced photocatalytic activity under visible light irradiation. Appl. Surf. Sci. 2017, 418, 147-155. [CrossRef]

18. Cheng, H.X.; Wang, X.X.; Hu, Y.W.; Song, H.Q.; Huo, J.R.; Li, L.; Qian, P.; Song, Y.J. Ag@ZnO core-shell nanoparticles study by first principle: The structural, magnetic and optical properties. J. Solid State Chem. 2016, 244, 181-186. [CrossRef]

19. Zhao, Y.; Cui, T.; Wu, T.; Jin, C.; Qiao, R.; Qian, Y.; Tong, G. Polymorphous ZnO Nanostructures: Zn Polar Surface-Guided Size and Shape Evolution Mechanism and Enhanced Photocatalytic Activity. ChemCatChem 2017, 9, 3180-3190. [CrossRef]

20. Abbas, K.N.; Bidin, N. Morphological driven photocatalytic activity of ZnO nanostructures. Appl. Surf. Sci. 2017, 394, 498-508. [CrossRef]

21. Zhang, H.; Lu, S.; Xu, W.; Yuan, F. First-principles study of electronic structures and photocatalytic activity of low-Miller-index surfaces of ZnO. J. Appl. Phys. 2013, 113, 034903. [CrossRef]

22. Warschkow, O.; Chuasiripattana, K.; Lyle, M.J.; Delley, B.; Stampfl, C. Cu/ZnO (0001) under oxidating and reducing conditions: A first-principles survey of surface structures. Phys. Rev. B 2011, 84, 125311. [CrossRef]

23. Lyle, M.J.; Warschkow, O.; Delley, B.; Stampfl, C. Molecular adsorption and methanol synthesis on the oxidized $\mathrm{Cu} / \mathrm{ZnO}(0001)$ surface. Surf. Sci. 2015, 641, 97-104. [CrossRef]

24. Nishidate, K.; Yoshizawa, M.; Hasegawa, M. Energetics of Mg and B adsorption on polar zinc oxide surfaces from first principles. Phys. Rev. B 2008, 77, 035330. [CrossRef]

25. Chen, X.; Huang, D.; Deng, W.J.; Zhao, Y.J. Structural stability and magnetic properties of Co-doped or adsorbed polar-ZnO surface. Phys. Lett. A 2009, 373, 391-395. [CrossRef] 
26. Yang, Z.; Xiong, S.J. Adsorption of Ag and Au atoms on wurtzite ZnO (0001) surface. Surf. Sci. 2011, 605, 40-45. [CrossRef]

27. Zhang, H.; Lu, S.; Xu, W.; Yuan, F. First-principles study of Si atoms adsorbed on ZnO (0001) surface and the effect on electronic and optical properties. Surf. Sci. 2014, 625, 30-36. [CrossRef]

28. Zhai, B.G.; Yang, L.; Ma, Q.L.; Huang, Y.M. Visible light driven photocatalytic activity of Fe-doped ZnO nanocrystals. Funct. Mater. Lett. 2016, 10, 1750002. [CrossRef]

29. Cao, H.; Zhou, Z.; Zhou, X.; Cao, J. Tunable electronic properties and optical properties of novel stanene/ZnO heterostructure: First-principles calculation. Comput. Mater. Sci. 2017, 139, 179-184. [CrossRef]

30. Xue, Y.; Yang, X.; Li, L.; Song, Q. First-principles calculations of electronic structure and optical properties of boron-phosphorus co-doped zinc oxide. Mater. Sci. Semicond. Proc. 2015, 30, 406-412. [CrossRef]

31. Su, Y.L.; Zhang, Q.Y.; Zhou, N.; Ma, C.Y.; Liu, X.Z.; Zhao, J.J. Study on Co-doped ZnO comparatively by first-principles calculations and relevant experiments. Solid State Commun. 2017, 250, 123-128. [CrossRef]

32. Abdel-Baset, T.A.; Fang, Y.W.; Anis, B.; Duan, C.G.; Abdel-Hafiez, M. Structural and Magnetic Properties of Transition-Metal-Doped $\mathrm{Zn}_{1-x} \mathrm{Fe}_{x} \mathrm{O}$. Nanoscale Res. Lett. 2016, 11, 1-12. [CrossRef] [PubMed]

33. Kim, Y.S.; Chung, Y.C. First-principles calculation of electronic structure and magnetic properties of copper adsorbed polar-ZnO surface. J. Vac. Sci. Technol. B 2007, 25, 2616-2618. [CrossRef]

34. Xia, S.; Liu, L.; Kong, Y.; Wang, H.; Wang, M. Study of Cs adsorption on (100) surface of [001]-oriented GaN nanowires: A first principle research. Appl. Surf. Sci. 2016, 387, 1110-1115. [CrossRef]

35. Sun, W.; Jha, J.K.; Shepherd, N.D.; Du, J. Interface structrues of $\mathrm{ZnO} / \mathrm{MoO}_{3}$ and their effect on workfunction of $\mathrm{ZnO}$ surfaces from first principles calculations. Comput. Mater. Sci. 2018, 141, 162-169. [CrossRef]

36. Sun, W.; Li, Y.; Jha, J.K.; Shepherd, N.D.; Du, J. Effect of surface adsorption and non-stoichiometry on the workfunction of $\mathrm{ZnO}$ surfaces: A first principles study. J. Appl. Phys. 2015, 117, 165304. [CrossRef]

37. Strak, P.; Kempisty, P.; Sakowski, K.; Krukowski, S. Ab initio determination of electron affinity of polar nitride surfaces, clean and under Cs coverage. J. Vac. Sci. Technol. A Vac. Surf. Films 2017, 35, 021406. [CrossRef]

38. Farooq, R.; Mahmood, T.; Anwar, A.W.; Abbasi, G.N. First-principles calculation of electronic and optical properties of graphene like $\mathrm{ZnO}$ (G-ZnO). Superlattices Microstruct. 2016, 90, 165-169. [CrossRef]

39. Hou, Q.; Jia, X.; Xu, Z.; Zhao, C.; Qu, L. Effects of Li doping and point defect on the magnetism of ZnO. Ceram. Int. 2017, 44, 1376-1383. [CrossRef]

40. Wu, M.; Sun, D.; Tan, C.; Tian, X.; Huang, Y. Al-Doped ZnO Monolayer as a Promising Transparent Electrode Material: A First-Principles Study. Materials 2017, 10, 359. [CrossRef] [PubMed]

41. Tan, C.; Sun, D.; Xu, D.; Tian, X.; Huang, Y. Tuning electronic structure and optical properties of ZnO monolayer by Cd doping. Ceram. Int. 2016, 42, 10997-11002. [CrossRef]

42. Liu, H.; Zhang, J.M. Structural, electronic, magnetic and optical properties of $\mathrm{Zn}_{1-} \mathrm{Ni}_{x} \mathrm{O}$ from first-principles. J. Phys. Chem. Solids 2017, 104, 267-275. [CrossRef]

43. Xie, L.Y.; Zhang, J.M. The structure, electronic, magnetic and optical properties of the Mn doped and Mn-X $\left(\mathrm{X} \frac{1}{4} \mathrm{~F}, \mathrm{Cl}, \mathrm{Br}\right.$, I and At) co-doped monolayer $\mathrm{WS}_{2}$ : A first-principles study. J. Alloys Compd. 2017, 702, $138-145$. [CrossRef]

44. Wróbel, J.; Piechota, J. On the structural stability of ZnO phases. Solid State Commun. 2008, 146, $324-329$. [CrossRef]

45. Decremps, F.; Datchi, F.; Saitta, A.M.; Polian, A. Local structure of condensed zinc oxide. Phys. Rev. B 2003, 68, 104101. [CrossRef]

46. Wei, S.; Wang, Z.; Yang, Z. First-principles studies on the Au surfactant on polar ZnO surfaces. Phys. Lett. A 2007, 363, 327-331. [CrossRef]

47. Strak, P.; Sakowski, K.; Kempisty, P.; Krukowski, S. Structural and electronic properties of AlN(0001) surface under partial N coverage as determined by ab initio approach. J. Appl. Phys. 2015, 118, 095705. [CrossRef]

48. Kempisty, P.; Krukowski, S. Adsorption of ammonia at GaN(0001) surface in the mixed ammonia/hydrogen ambient-A summary of ab initio data. AIP Adv. 2014, 4, 117109. [CrossRef]

49. Qiao, L.; Zeng, Y.; Qu, C.Q.; Zhang, H.Z.; Hu, X.Y.; Song, L.J.; Bi, D.M.; Liu, S.J. Adsorption of oxygen atom on Zn-terminated (0001) surface of wurtzite ZnO: A density-functional theory investigation. Physica E 2013, 48, 7-12. [CrossRef]

50. Lahmer, M.A. Hydrogen sensing properties of the (0001) surface enhanced by Be doping: A first principles study. Sens. Actuators B Chem. 2015, 221, 906-913. [CrossRef] 
51. Shaoqiang, G.; Qingyu, H.; Zhenchao, X.; Chunwang, Z. First principles study of magneto-optical properties of Fe-doped ZnO. Physica B 2016, 503, 93-99. [CrossRef]

52. Pawar, R.C.; Choi, D.H.; Lee, J.S.; Lee, C.S. Formation of polar surfaces in microstructured ZnO by doping with $\mathrm{Cu}$ and applications in photocatalysis using visible light. Mater. Chem. Phys. 2015, 151, 167-180. [CrossRef] 